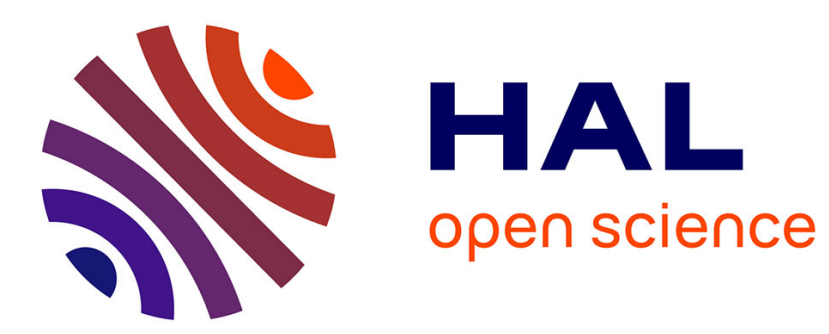

\title{
Incentives, Reputation and the Allocation of Authority
}

Florian Englmaier, Ales Filipi, Ravi Singh

\section{To cite this version:}

Florian Englmaier, Ales Filipi, Ravi Singh. Incentives, Reputation and the Allocation of Authority. Journal of Economic Behavior and Organization, 2010, 76 (2), pp.413. 10.1016/j.jebo.2010.06.011. hal-00870189

\section{HAL Id: hal-00870189 \\ https://hal.science/hal-00870189}

Submitted on 6 Oct 2013

HAL is a multi-disciplinary open access archive for the deposit and dissemination of scientific research documents, whether they are published or not. The documents may come from teaching and research institutions in France or abroad, or from public or private research centers.
L'archive ouverte pluridisciplinaire HAL, est destinée au dépôt et à la diffusion de documents scientifiques de niveau recherche, publiés ou non, émanant des établissements d'enseignement et de recherche français ou étrangers, des laboratoires publics ou privés. 


\section{Accepted Manuscript}

Title: Incentives, Reputation and the Allocation of Authority

Authors: Florian Englmaier, Ales Filipi, Ravi Singh

PII:

DOI:

S0167-2681(10)00127-7

Reference: doi:10.1016/j.jebo.2010.06.011

JEBO 2568

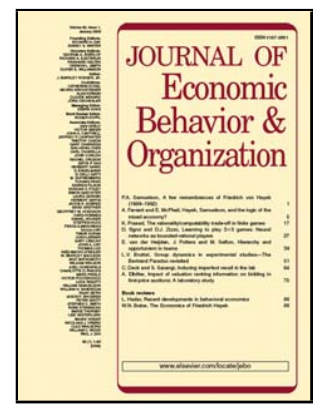

To appear in: Journal of Economic Behavior \& Organization

Received date: $\quad 9-6-2006$

Revised date: $\quad 21-6-2010$

Accepted date: $\quad 30-6-2010$

Please cite this article as: Englmaier, F., Filipi, A., Singh, R., Incentives, Reputation and the Allocation of Authority, Journal of Economic Behavior and Organization (2010), doi:10.1016/j.jebo.2010.06.011

This is a PDF file of an unedited manuscript that has been accepted for publication. As a service to our customers we are providing this early version of the manuscript. The manuscript will undergo copyediting, typesetting, and review of the resulting proof before it is published in its final form. Please note that during the production process errors may be discovered which could affect the content, and all legal disclaimers that apply to the journal pertain. 


\title{
Incentives, Reputation
}

\author{
and the
}

\section{Allocation of Authority*}

\author{
Florian Englmaier ${ }^{\dagger} \quad$ Ales Filipi $^{\ddagger} \quad$ Ravi Singh ${ }^{\S}$
}

First Version: January 2002; Revised, February 2010

\begin{abstract}
We address the question how much authority a principal should delegate to a manager with conflicting interests and uncertain ability in a context in which the manager has both compensationbased and reputational incentives. The optimal level of authority balances the value of the manager's decision-making expertise against the cost of ensuring that the manager uses his discretion productively. Reputational incentives reduce the necessary monetary incentives to discourage purely opportunistic behavior, but may cause the manager to pursue conservative courses of action to preserve his reputation. This undermines the benefits of delegating control, leading to decreased managerial authority and stronger monetary incentives. When the principal contracts with the manager repeatedly, she delegates additional authority early in the relationship in order to screen for managers of high ability. Decentralization of decision making may thus occur even if the static benefits from decentralization are negative.
\end{abstract}

JEL Classifications: D86, L14, L23, M52, M54

Keywords: Agency Problems; Delegation; Compensation Contracts; Job Design; Career Concerns; Managerial Conservatism

${ }^{*}$ We would like to thank Susan Athey, George Baker, Marco Celentani, Jonathan Levin, Ilya Segal, Steve Tadelis, and Frédèric Warzynski for helpful comments and valuable feedback. We have also significantly benefitted from the constructive comments by the coeditor, Claude Menard, and two anonymous referees. All remaining errors are our own.

${ }^{\dagger}$ Corresponding Author: University of Munich, Ludwigstr. 28 III VG, 80539 Munich, Germany, Phone: +49 892180 3916, Fax: +49 89218099 3916, englmaier@lmu.de

${ }^{\ddagger}$ Bates White, ales.filipi@bateswhite.com

${ }^{\S}$ Harvard University, rsingh@hbs.edu 


\section{INTRODUCTION}

Delegating control over production and investment decisions enables managers to better utilize their information, knowledge, and skills. Investors, for example, transfer control over their capital to entrepreneurs and professional managers precisely because they expect that managers can use the funds more productively. However, managers with a free hand may squander investors' capital either inadvertently through poor decision-making or by knowingly undertaking unproductive projects from which they derive personal benefit. A principal can address potential conflicts of interest either by using incentive contracts or by simply limiting the authority of a manager. In practice, parties write contracts which use both of these instruments. For example, Kaplan and Stromberg (2003) find that the contracts between venture capitalists and entrepreneurs both specify claims on cash-flows (incentives) and allocate a constellation of control rights (authority) which are typically contingent on performance.

In this paper, we develop a dynamic principal-agent model and analyze how a manager's concern about his reputation and the horizon of the relationship between a principal and manager affect the allocation of authority and the design of compensation. In our framework, a manager has potentially better information than the principal about the firm's best course of action. To benefit from this information, the principal must grant the manager some decision-making authority. Like Holmström (1984), we model authority as the freedom to choose from a certain set of actions; expanding the set of actions allows the manager to use his information more efficiently, but is costly since the manager can engage in opportunistic behavior. The key difference between our model and the existing literature is that we allow for both explicit incentives (compensation contracts) and implicit incentives (concerns about future career opportunities). ${ }^{1}$

In order to isolate the effects that are relevant for our analysis of the dynamic problem we start by analyzing a static setting. We find that the optimal level of discretion is determined by balancing the value of the manager's information against the cost of the explicit incentives required to ensure that the manager uses his authority productively. Whenever the manager has an informational advantage over the principal, the principal grants him authority and provides explicit incentives.

The primary focus of our analysis is on how dynamic considerations impact either the benefit or the cost side of this tradeoff between utilizing the manager's superior information and limiting the cost of compensation. The quality of the manager and his ability to generate useful information is uncertain,

\footnotetext{
${ }^{1}$ Related papers include, for example, Alonso and Matouschek (2008) and Krishna and Morgan (2008). We defer the discussion of the relationship of our paper to the literature to Section 5.
} 
introducing a role for reputational concerns. We find that these concerns always make managers less inclined to abuse their discretion and pursue private benefits. Career concerns thus lower the explicit compensation necessary to discourage opportunism. However, we also find that career concerns can lead managers to ignore their private information (the very reason for granting them authority) and avoid taking actions that place their reputation at risk. In such a scenario, it is optimal for a principal to both limit a manager's discretion (centralize decision-making) and to increase the reward for taking risks.

An important result from our analysis is that whether career concerns decrease the incentives of managers to use their authority productively depends on the returns to building a better reputation. When the potential gain in reputational capital from taking risks is high relative to the potential loss (i.e., when a manager's future compensation is convex in his perceived talent), managers have an incentive to act on their private information to distinguish themselves as superior decision-makers. In this case, career concerns lower the amount of explicit incentive compensation necessary to induce managers to use their discretion productively; the principal takes advantage of the improved alignment by granting managers greater authority than in the case without career concerns. On the other hand, if managers primarily fear damaging their reputations, such as when poor performance vastly diminishes their labor market opportunities, they avoid making decisions that are informative about their ability and choose conservative courses of action. In this circumstance, it is costly to induce managers to use their authority productively. ${ }^{2}$ A principal preempts a manager's tendency to act conservatively by both providing stronger incentives and further centralizing decision-making. Hence it is a unique implication of our analysis that implicit incentives substitute for the explicit incentives necessary to discourage obvious forms of opportunism, but may simultaneously force a principal to use stronger explicit incentives to encourage managers to act on their knowledge and take risks. For example, in the context of asset management, our theory suggests that a senior portfolio manager will counter the tendency of a junior portfolio manager to closely track his benchmark index and avoid risks by either closely supervising investment decisions or providing greater rewards for outperformance; i.e., managerial conservatism manifests itself not only directly through managerial behavior, but also indirectly through costly adaptations by organizations.

In much of our analysis, we assume that the principal has only a short-term relationship with a manager. In long-term relationships an important additional consideration arises, which unambigu-

\footnotetext{
${ }^{2}$ This bias towards conservative actions is reminiscent of the literature on "herding". There, under certain circumstances, managers want to avoid "standing out", ignore substantive private information, and simply mimic the investment decisions of other managers, which results in inefficient investment decisions.
} 
ously increases a manager's level of authority. The success or failure of a project is revealing about a manager's ability only to the extent that the manager has decision-making authority. In the extreme case, if an employee is simply told which action to take by a superior, there is little basis for evaluating the employee's capabilities. Consequently, discretion has informational benefits and allows future employers and lenders to learn about the ability of managers. When the principal expects to have an extended relationship with the manager, she internalizes this information externality, and increases the manager's level of discretion at the outset of the relationship.

The next section introduces the baseline model, which illustrates the basic tradeoffs, and links discretion to reputation, the value of information, and conflicts of interest in a static setting. Section 3 extends the model to a two-period setting and analyzes the role of career concerns. While in Section 3 we assume that the relationship between any principal and any manager lasts only one period, Section 4 analyzes the consequences of extending the relationship to both periods. Finally, Section 5 relates our analysis to the literature and Section 6 concludes. The Appendix contains all proofs.

\section{The Static Model}

To analyze the tradeoff between retaining control and granting greater discretion, we construct a model in which a principal (she) and a manager (he) enter into a contractual relationship and undertake a project. The manager has potentially better information about the optimal course of action, and the principal can benefit from this information only by giving the manager discretion over the project. However, two factors make discretion costly: (i) uncertainty about the manager's talent and (ii) conflicts of interest. Here, we describe the informational structure, incongruity between the principal's and agent's preferences, and contracting environment, and solve the basic model to set the stage for the dynamic analysis in the subsequent sections.

\subsection{Information, Projects, and Payoffs}

To capture the manager's superior information, we assume that the manager privately receives a signal $s$ about the state of world $\omega$. $\omega$ is drawn from a distribution $F(\omega)$ with support $[0,1]$ and a strictly positive density, $f(\omega)$. There are two types of managers: informed (high types) and uninformed (low types). $s=\omega$ for an informed manager, while $s$ is an independent draw from $F($.$) for an uninformed$ manager. In other words, the manager is either perfectly informed or completely uninformed. Neither the principal nor the manager know the manager's type. Intuitively, imagine a novice manager who 
does not yet know whether or not he is good at his job and hence has in this respect no informational advantage over his employer. Only over time his true ability is revealed. The assumption is important because it rules out ex ante asymmetric information between the two parties, which could potentially be mitigated by screening mechanisms (see Footnote 3 ). The probability that the manager is informed is $\theta$ and is common knowledge. We identify the manager's reputation with beliefs about his type, which in the static model is fixed at the prior $\theta$.

There is a continuum of possible actions $a \in[0,1]$. The profitability $\pi$ of action $a$ depends on the state of the world, and it is 1 if $a=\omega$ and zero otherwise. Therefore, an informed manager can generate a profit of 1 by choosing an action equal to his observed signal, while an uninformed manager generates an expected profit of 0 . This $0-1$ setup does not drive the results, but simplifies the analysis as follows: (i) it simplifies the principal's inference problem as low types cannot get lucky and generate high profit and (ii) it reduces the complexity of the set of monetary contracts as the realized profit is a simple discrete variable.

In addition to $a \in[0,1]$, there is an action $\bar{a}$, which maintains the status quo and yields a profit of $R$, independent of the state of the word. We refer to $\bar{a}$ as the "standard action". A crucial feature of the standard action, especially relevant in a dynamic context, is that the manager can avoid inferences about his ability by taking this action. For example, each value of a might represent a possible acquisition, the size of which is increasing in $a$. In this case, the action $\bar{a}$ corresponds to not acquiring any firm at all, and $\omega$ is the optimal acquisition. So choosing $\bar{a}$ is equivalent to following a conservative course of action that does not require particularly outstanding abilities and is hence not informative with respect to the manager's talent. ${ }^{3}$

\footnotetext{
${ }^{3}$ If the manager privately knew his type, he would never generate zero profit. High types would always follow their signal (unless they were constrained to take the standard action) and low types would never follow their signal and instead choose the standard action. Given this behavior, the choice of the standard action would reveal some of the manager's private information to the principal. In the extreme, the principal could grant the manager full discretion. If the manager took the standard action, the principal would conclude with certainty that the manager is the low type because the high type, having full discretion, would never find it profitable to take the standard action. The assumption of private information would not qualitatively change our results in the static model, since the information learned in that model has no value to the principal (there is no continuation). It would impact the analysis of the dynamic model in two ways. First, the effect of career concerns would be limited to disciplining the manager not to blatantly abuse authority. The concept of negative "returns to reputation-building" would not arise because high types are always willing to take informationally intensive actions, while low types always avoid them. Second, the principal would have an incentive to grant more discretion in the first period in order to make a more accurate inference from the manager having taken the standard action (we analyze an analogous effect in Section 4).
} 
When the manager acts on his information he generates a profit of 1 with probability $\theta$, i.e. the probability that his signal accurately reflects the state of the world. A benchmark profit of $R$ can be generated without any information by simply always taking the standard action. Hence $\theta-R$ represents the expected value of the manager's information. To make the problem interesting we assume that $\theta>R$ as the reason for giving the manager discretion is precisely to allow the manager to exploit his information and increase the profit of the project.

However, the interests of the manager are not perfectly aligned with those of the principal. We assume that the manager derives a private non-contractible benefit from taking actions, $b(a)$ with $b^{\prime}(a)>0$. This implies that, all else equal, the manager prefers to take larger actions. For example, if each action $a$ represents a possible acquisition, $b(a)$ captures the manager's predilection for large acquisitions or "empire-building". We assume that $b(1)<R$, which implies that private benefits are small relative to the cash-flows of the project, and that it is always efficient to induce the manager to take profitable actions rather than maximize private benefits. Furthermore we assume that $b(0)=$ $b(\bar{a})=0$, i.e. the standard action does not yield any private benefits. The last assumption simplifies the exposition but our results are qualitatively unchanged as long as $R+b(\bar{a})<\theta$, i.e. as long as it is efficient to utilize the manager's information.

The manager is risk-neutral with respect to his monetary income, $m$, and his utility is given by

$$
u(m, a)=m+b(a) .
$$

Unlike the manager, the principal values only the profits from the project and is risk-neutral as well. We assume that the manager is wealth constrained. The assumption approximates the (presumably fairly typical) situation where the cash flows of the project are large relative to the personal wealth of the manager. It rules out the possibility to implement the first best by making the risk-neutral manager residual claimant, which amounts to selling the project.

\subsection{CONTRACTS}

The principal limits the manager's opportunistic behavior by restricting the set of actions under his control. Formally, the principal chooses a compact set $\mathcal{A}$, where $\mathcal{A} \subseteq[0,1]$, and allows the manager to choose actions only from $\mathcal{A}$ or $\mathcal{A} \cup\{\bar{a}\}$, depending on whether the standard action is included in the manager's choice set. ${ }^{4}$ We say that the manager has more authority if he has a larger set of actions from which to choose, or, formally, $\mathcal{A}$ gives the agent more discretion than $\mathcal{A}^{\prime}$ if $\mathcal{A}^{\prime} \subset \mathcal{A}$.

\footnotetext{
${ }^{4}$ Compactness is necessary to ensure existence of the maximum in the manager's choice program.
} 
The assumption that the principal can ex ante limit the manager to a certain set of actions is made primarily for expositional reasons. Alternatively, we could assume that the manager always reports to the principal, who either approves or discards his suggestion. In this alternative approach, a manager effectively has more discretion - or what Aghion and Tirole (1997) call real authority - when the principal is more likely to accept his proposals. An appendix in Englmaier et al. (2010) analyzes the problem using this latter approach.

The other instrument the principal uses to limit the opportunistic behavior of the manager is explicit monetary incentives. She offers the manager a compensation package tied to the profits of the project. While the principal can offer contracts contingent on profit, we assume that compensation cannot be made contingent on the action. In this regard, contracts are incomplete (see Grossman and Hart, 1986, and Hart and Moore, 1990). We make this assumption mainly to simplify the analysis. However, there is arguably a tension in the assumption that the principal can restrict the manager's set of actions, but cannot write compensation contracts that depend on actions. In an appendix in Englmaier et al. (2010), we remove this assumption and allow for compensation contracts to be contingent on all observable variables. The results are qualitatively similar, since it is the asymmetry of information that forces the principal to grant the manager effective control.

We denote by $\beta$ (bonus) and $\sigma$ (salary) the payments to the manager when the profit is 1 and $R$, respectively. The principal never finds it optimal to offer a payment when the profit is 0 , since the manager is risk-neutral. As the manager is protected by limited liability, all payments must be non-negative. Furthermore, since $b(\bar{a})=0$, we can assume without loss of generality that the standard action is always included in the choice set of the manager. In particular, if the principal does not want the manager to take the standard action, she can simply set $\sigma=0$. Though the choice set of the manager is formally $\mathcal{A} \cup\{\bar{a}\}$, we henceforth abuse notation and simply refer to the set as $\mathcal{A}$.

Summarizing, a contract specifies the manager's compensation and authority and has the form $\{\beta, \sigma, \mathcal{A}\}$. Once the terms of the contract have been set, the manager privately observes his signal, $s$, and chooses an action. The action and the state of the world determine the project's profits, which in turn, determines the managers compensation. 


\subsection{The Optimal Contract}

Given a contract $C=\{\beta, \sigma, \mathcal{A}\}$ and a signal $s$, the manager's expected utility from taking action $a$ is

$$
E[u \mid s, C]= \begin{cases}\theta \beta+b(s) & \text { if } a=s \\ \sigma & \text { if } a=\bar{a} \\ b(a) & \text { otherwise. }\end{cases}
$$

Let $a^{*}(s, C)$ be the manager's best response. ${ }^{5}$ In addition, let $l \equiv \max \mathcal{A}$ be the largest action that the manager can take. If the manager chooses to maximize his private benefit, he will choose $a=l$, since $b(a)$ is increasing in $a$, and his payoff is $b(l)$. For $s \in \mathcal{A}$, the manager's payoff from taking the action corresponding to his signal $(a=s)$ is given by the first line of equation (1). In particular, the manager receives the payment $\beta$ if his information is correct, in addition to the private benefit derived from taking the action. The manager, like the principal, does not know whether or not he is informed and hence receives $\beta$ with probability $\theta$. Finally, the manager can choose the standard action, $\bar{a}$, for a payoff of $\sigma$. Note that one of these three actions always weakly dominates any other action; that is, $a^{*}(s, C) \in\{s, \bar{a}, l\}$.

The principal's expected payoff is $\theta(1-\beta)$ from action $s, R-\sigma$ from $\bar{a}$, and 0 from $l$. The principal's expected payoff from contract $C$ is therefore:

$$
V(C, \theta)=\theta(1-\beta) \operatorname{Pr}\left[a^{*}(s, C)=s\right]+(R-\sigma) \operatorname{Pr}\left[a^{*}(s, C)=\bar{a}\right] .
$$

The optimal choice of $C$ maximizes $V(C, \theta)$. The following lemma provides a partial characterization of the optimal contract:

Lemma 1 For any contract $C$, there is a contract $\tilde{C}$ that (i) allows the manager to choose an action from an interval $[k, l]$; (ii) induces the manager to utilize his information whenever possible and to choose the standard action otherwise (e.g., $a^{*}(s, \hat{C})=s$ for $s \in[k, l]$ and $a^{*}=\bar{a}$ otherwise); and (iii) gives the principal at least as much utility as $C$.

Proof. The proof of this lemma and all other proofs are collected in Appendix A.

Lemma 1 allows us to restrict the search for the optimal $\mathcal{A}$ to intervals. Also, we need only consider contracts in which the manager takes the action corresponding to his signal when he has the authority

\footnotetext{
${ }^{5} \operatorname{In}$ particular, $a^{*}(s, C) \in \arg \max _{a \in \mathcal{A}} E[u \mid s, C]$. Without loss of generality, we assume that $a^{*}(s, C)$ is a pure strategy. Roughly speaking, mixed strategies can be ruled out since the principal always has a preferred action she would like the manager to take. Therefore, if the manager's response involves mixing across actions, the principal responds by slightly adjusting the compensation payments.
} 
to do so and the standard action when he lacks authority. To the extent that it is costly to induce the manager to behave that way (as we will shortly see), the optimal contract does not generally give the manager full discretion. In order to simplify the analysis of optimal intervals $[k, l]$, we assume throughout the rest of the paper that the marginal private benefit of action $a$ normalized by the likelihood of that action being optimal is strictly increasing.

Assumption $1 b^{\prime}(a) / f(a) \equiv v(a)$ is strictly increasing.

The function $v(a)$ can be considered a measure of the severity of conflict of interests. Intuitively, when there is little likelihood that the optimal action is in the neighborhood of $a$, but there is an opportunity to extract greater private benefit, the conflict of interests is severe at $a$. Imagine, for example, that the principal must decide whether to increase the manager's budget by $\$ 10$ million, which would allow the manager to invest in a new technology whose cost exceeds his current budget. Also imagine that the manager would derive an incremental private benefit of $\$ 1$ million from the investment. The propensity of the manager to lobby for the budget increase is the same irrespective of the likelihood that the investment in the new technology is optimal. However, the likelihood of the optimality of the technology determines the principal's attitude towards the manager's lobbying efforts. If the probability that the new technology is optimal is $1 \%$, the principal will be rather opposed to the manager's request; if the probability is $60 \%$, he will be more willing to consider it. In this sense, the conflict of interest between the principal and the manager is more severe in the former case than the latter. ${ }^{6}$

Under Assumption 1, the optimal choice of $\mathcal{A}$ places an upper bound on the actions that the manager can take (e.g., places limits on the size of investments), while allowing complete discretion below that bound. The following proposition formalizes this intuition:

Proposition 1 The optimal interval of discretion has the form $[0, l]$.

\footnotetext{
${ }^{6}$ Another interpretation of $v(a)$ is the minimum value the manager must be able to generate to make the principal willing to give the manager more discretion in the neighborhood of $a$. To see this, suppose that the principal must decide whether to give the manager more discretion, by extending $\mathcal{A}$ from $[k, l]$ to $[k, l+\epsilon]$. The benefit to expanding the discretion of the manager is the increased probability that the optimal action is taken, times the value that the optimal action generates: $(F(l+\epsilon)-F(l)) v \equiv \Delta F v$. The cost of expanding discretion comes from the the fact that, if the manager chooses to behave opportunistically, he can increase his private benefit by $b(l+\epsilon)-b(l) \equiv \Delta b$. The principal can induce the manager not to abuse his discretion and still benefit only if $\Delta F v \geq \Delta b$. Dividing by $\epsilon$ and taking the limit as $\epsilon$ goes to zero, the equation becomes, $f(l) v \geq b^{\prime}(l)$ or $v(l) \geq b^{\prime}(l) / f(l)$.
} 
Proposition 1 reduces the choice of $\mathcal{A}$ to a univariate problem. In particular, the degree of discretion granted to the manager can be identified with $l$. Managers with a higher limit have greater freedom to choose the course of action.

The incentive compatibility conditions associated with any contract satisfying Lemma 1 and Proposition 1 are

$$
\begin{aligned}
& \sigma \geq b(l) \\
& \theta \beta+b(a) \geq \sigma \text { for } a \in[0, l]
\end{aligned}
$$

where equation (3) ensures that the manager always prefers the standard action over the action that maximizes his private benefit, while equation (4) ensures that the manager takes the action corresponding to his signal whenever possible. Note that if condition (4) holds at $a=0$, then the inequality holds for all $a$ and that, for a contract to be optimal, the incentive compatibility conditions must bind at $a=0$. Therefore, equations (3) and (4) reduce to

$$
\theta \beta=\sigma=b(l)
$$

which provides a simple relationship between $\beta, \sigma$, and $l$, and establishes that the manager's compensation package is increasing in the level of discretion, i.e. managers with extensive control over a project must be compensated generously in order not to abuse their discretion. These results are summarized in the next corollary:

Corollary 1 The incentive payments of the optimal contract must satisfy $\theta \beta=\sigma=b(l)$, implying that incentives are increasing in the level of discretion.

\subsection{The Allocation of Authority}

Given Corollary 1, the principal's problem reduces from selecting the triple $\{\beta, \sigma, \mathcal{A}\}$ to selecting the best contract of the form $\{b(l) / \theta, b(l),[0, l]\}$, i.e. choosing the optimal $l$. Substituting $\{b(l) / \theta, b(l),[0, l]\}$ and the managers best response, $a^{*}(s)$, into the principal's profit function (equation (2)) yields the following maximization problem: ${ }^{7}$

$$
\max _{l \in[0,1]} \quad V(l)=R+(\theta-R) F(l)-b(l)
$$

\footnotetext{
${ }^{7}$ Omitted from the principal's maximization problem is a participation constraint. We implicitly assume that the rents the manager receives in order to make the optimal contract incentive compatible exceed his reservation utility. If the rents are not sufficient, the principal will increase $l$ till $\beta(l)$ and $\sigma(l)$ provide the required level of compensation.
} 
The profit function reflects the fact that the principal can always earn at least $R$; and by giving the manager a level of discretion $l$ and a compensation package with an expected value of $b(l)$, the principal can earn an additional profit of $\theta-R$ with probability $F(l)$. We restrict attention to interior optima. The existence of an interior optimum is ensured if the conflict of interests in the neighborhood of zero is not too severe and the conflict of interests in the neighborhood of one is severe. ${ }^{8}$ The first-order condition is

$$
(\theta-R) f(l)=b^{\prime}(l)
$$

or equivalently

$$
\theta-R=v(l)
$$

The marginal benefit of increasing the manager's discretion is the expected value of the manager's information, $\theta-R$, times the increased likelihood, $f(l)$, that the manager will be able to utilize his information. The marginal cost of greater discretion is $b^{\prime}(l)$, which reflects the higher expected compensation required to induce the manager to take the correct action. Equivalently, at the optimal level of discretion, the value of the manager's information must equal the minimum value, $v(l)$, required to resolve the conflict of interests at the margin. Hence, the optimal degree of discretion is determined by trading off the benefits of decentralized decision-making against the costs created by conflicts of interest. The next proposition establishes that there is a unique level of discretion which maximizes the principal's profit, and summarizes how discretion varies with the parameters of the model:

Proposition 2 The optimal level of discretion is unique and is given by the solution to equation (7). In addition, the optimal level of discretion increases in the potential benefit from better decision making, $1-R$, increases in reputation, $\theta$, and decreases in the severity of the conflict of interests, $v$.

Proposition 2 is consistent with casual observation. Activities which are not easily standardized and which are information intensive, warrant greater delegation of control. In addition, management positions involving a high degree of discretion are filled by individuals with high perceived ability (high $\theta$ ) and offer generous incentive compensation.

\section{The Dynamic Model}

We now extend our analysis to a dynamic setting in which the manager's current choices influence his future reputation. We do so by a simple repetition of the static model over two periods. In this

\footnotetext{
${ }^{8}$ Formally, $v(0)<(\theta-R)<v(1)$ must hold. A sufficient condition for the existence of an interior optimum is that the private benefit, $b(a)$, satisfies $b^{\prime}(0)=0$ and $b^{\prime}(1)=+\infty$, an analog of the Inada conditions on production functions.
} 
section, we assume that the relationship between the principal and the manager lasts for only one period and in the second period the manager forms a relationship with a new employer. In Section 4, we consider the case in which the principal may have an extended relationship with the manager. The assumption, that the length of the relation is exogenously fixed to one period is for example sensible in environments in which deals are made on a project by project basis. In that case, as for example argued in Holmström (1999), implicit incentives are provided by the labor (or capital) market, which uses the manager's past performance as the basis for determining his level of compensation and authority in subsequent relationships. The notation for all variables is the same, except a time subscript is added to indicate the period. The manager maximizes the expectation of the discounted sum of the single-period utilities, $U=u_{1}+\delta u_{2}$, where $\delta$ is the discount factor and $u_{i}$ is the manager's payoff in time period $i$.

\subsection{The First-Period Equilibrium}

As in the static model, the principal and the manager enter the first period with a common belief $\theta$ that the manager is informed. The market then observes the manager's choice of $a_{1}$ and the resulting profit $\pi_{1}$ and updates its belief to $\hat{\theta}\left(a_{1}, \pi_{1}\right)$. In the second period, the manager enters into a new contract with a new principal. In the analysis that follows, we derive a perfect Bayesian equilibrium. We require that (i) the second-period contract and the manager's best response must be optimal given $\hat{\theta}\left(a_{1}, \pi_{1}\right)$; (ii) the first-period contract and the manager's best response must be optimal given the second-period strategies; and (iii) beliefs $\hat{\theta}\left(a_{1}, \pi_{1}\right)$ must be consistent with Bayes rule whenever possible.

Using backward induction, the optimal contract in the second period is equal to the optimal contract derived in the analysis of the static model. Specifically, the second-period contract is

$$
\left\{\beta_{2}^{*}, \sigma_{2}^{*}, \mathcal{A}_{2}^{*}\right\}=\left\{b\left(l_{2}(\hat{\theta})\right) / \hat{\theta}, b\left(l_{2}(\hat{\theta})\right),\left[0, l_{2}(\hat{\theta})\right]\right\}
$$

where $l_{2}(\hat{\theta})$ solves equation (6) and is the optimal level of discretion for a manager with reputation $\hat{\theta}$. Again, the manager's best response in the second period is to take the action corresponding to his signal when possible and take the standard action otherwise. Slightly abusing notation, let $u_{2}(\hat{\theta})$ be the manager's expected utility from such a contract in the second period. Substituting the manager's best response into equation (1), we have that

$$
u_{2}(\hat{\theta}) \equiv E\left[u_{2} \mid \beta_{2}^{*}, \sigma_{2}^{*}, \mathcal{A}_{2}^{*}, \hat{\theta}\right]=b\left(l_{2}(\hat{\theta})\right)+\int_{0}^{l_{2}(\hat{\theta})} b(s) f(s) d s .
$$


The payoff is increasing in $\hat{\theta}$, so the manager unambiguously prefers to be perceived as a more informed type. Moreover, $u_{2}(0)=0$, so that the manager receives no compensation when he is believed to be the low type with certainty.

The following proposition characterizes the first-period contract and the manager's best response. As in the static model, the manager takes the action corresponding to his signal on an interval and the standard action otherwise. The market beliefs associated with this equilibrium are compelling: managers who utilize their information are inferred as low types if they earn low profits and high types if they earn high profits, and the inference is unchanged when managers earn the intermediate level of profit, $R$.

Proposition 3 There is a perfect Bayesian equilibrium, in which the first-period contract is of the form $\left\{\beta_{1}, \sigma_{1},\left[0, l_{1}\right]\right\}$. The manager's response, $a_{1}^{*}$, and the market's beliefs $\hat{\theta}$ are such that

$$
a_{1}^{*}=\left\{\begin{array}{cc}
s_{1} & s_{1} \in\left[0, l_{1}\right] \\
\bar{a} & \text { otherwise }
\end{array} \quad \text { and } \hat{\theta}=\left\{\begin{array}{cc}
1 & \text { if } \pi_{1}=1 \\
\theta & \text { if } \pi_{1}=R \\
0 & \text { if } \pi_{1}=0
\end{array}\right.\right.
$$

Moreover, the optimal incentive payments satisfy:

$$
\begin{aligned}
\sigma_{1} & =\max \left\{b\left(l_{1}\right)-\delta u_{2}(\theta), 0\right\} \\
\theta \beta_{1} & =\max \left\{\sigma_{1}+\delta\left(u_{2}(\theta)-\theta u_{2}(1)\right), 0\right\} .
\end{aligned}
$$

Notice that the incentive payments $\beta_{1}$ and $\sigma_{1}$ are functions of $u_{2}(\theta)$ and $u_{2}(1)$, the manager's secondperiod payoff when his reputation is $\theta$ and 1 , respectively. As before, explicit incentives are necessary to induce the manager to use his authority productively. However, in choosing an action in the first period, the manager must consider the impact of that action on his future compensation.

The equilibrium in Proposition 3 is not the unique equilibrium of the game. It can be shown, however, that the game has two classes of equilibria. The first class includes a continuum of equilibria in which the manager always takes the standard action. ${ }^{9}$ We consider such equilibria economically uninteresting. ${ }^{10}$ The second class includes equilibria in which the manager takes some actions from $[0,1]$ with a positive probability. In these equilibria, all three profit levels are observed and beliefs are

\footnotetext{
${ }^{9}$ These equilibria are supported by off-equilibrium path beliefs that "punish" successful managers. For example, (1) the principal in the first period offers an epsilon interval of discretion and zero monetary incentives, (2) the manager in the first period always takes the standard action, (3) the market beliefs are $\hat{\theta}(0)=0, \hat{\theta}(R)=\theta$, and $\hat{\theta}(1)=0$, (4) the contract offered and the manager's behavior in the second period are as derived in the static model.

${ }^{10}$ We conjecture that if the concept of sequential equilibrium, Kreps and Wilson (1982), was generalized to games with a continuum of actions, these "degenerate" equilibria would not be sequential equilibria.
} 
thus fully derived using Bayes law. It can be further shown that the equilibrium in Proposition 3 is the unique equilibrium in the second class. ${ }^{11}$

\subsection{Career Concerns and Explicit Incentives}

When the equilibrium incentive payments, $\beta_{1}$ and $\sigma_{1}$, are positive, equations (9) and (10) reduce to:

$$
\begin{aligned}
\sigma_{1} & =b\left(l_{1}\right)-\delta u_{2}(\theta) \\
\theta \beta_{1}-\sigma_{1} & =\delta\left(u_{2}(\theta)-\theta u_{2}(1)\right) .
\end{aligned}
$$

If the manager seeks to maximize his private benefit, he receives $b\left(l_{1}\right)$. In the static model (and thus in the second period of the dynamic model), the incentive payment $\sigma_{2}$ for a manager who is given discretion $l_{1}$ must equal $b\left(l_{1}\right)$ to discourage the manager from pursuing pure private benefits. In the first period, if the manager uses his discretion rather than takes the standard action, his performance will be poor, and the market will infer that he is not a capable manager. The manager will consequently lose $\delta u_{2}(\theta)$ in future compensation, in addition to losing any current incentive compensation. Hence, the manager is more hesitant to knowingly abuse his discretion if his reputation is at stake. The principal takes the career concerns into account and lowers the explicit incentive payment so that $\sigma_{1}=b\left(l_{1}\right)-\delta u_{2}(\theta)$. An immediate implication of equation (11) is that $\sigma_{1} \leq \sigma_{2}$, holding fixed the level of discretion $l$ and the reputation of the manager.

However, the effect of career concerns on the manager's willingness to utilize his private information is more subtle. While in the static setting $\theta \beta=\sigma$, equation (12) implies that $\theta \beta_{1}$ does not generally equal $\sigma_{1}$. Career concerns change the relative cost of inducing the manager to take informationintensive actions. Specifically, the relative cost is $\theta \beta_{1}-\sigma_{1}$ and depends on the term $\theta u_{2}(1)-u_{2}(\theta)$. If $\theta u_{2}(1)$ exceeds $u_{2}(\theta)$, a manager with reputation $\theta$ prefers a gamble in which his reputation is revealed relative to simply maintaining his current reputation. In such a gamble, the manager is revealed to be the high type with probability $\theta$ and receives future compensation $u_{2}(1)$; with probability $1-\theta$, the manager is revealed to be the low type and receives no future compensation. The difference $\theta u_{2}(1)-$ $u_{2}(\theta)$ is therefore the manager's net expected return from risking his current level of reputational capital (excluding any explicit period-one incentive payments).

Definition 1 The return to reputation-building is positive (negative) if $\theta u_{2}(1)-u_{2}(\theta) \geq(<) 0$.

If the return to reputation-building is positive, career concerns make the manager more inclined to

\footnotetext{
${ }^{11} \mathrm{~A}$ more formal treatment of this argument is given in an appendix in Englmaier et al. (2010).
} 
utilize his private information since doing so reveals his type and yields high expected reputational returns. In this case, the principal can lower the incentive payment for information-intensive actions relative to the standard action, implying that $\theta \beta_{1} \leq \sigma_{1}$. When the return to reputation-building is negative, the manager requires more generous compensation to take "revealing" actions, and we have that $\theta \beta_{1}>\sigma_{1}$. We summarize the preceding discussion with the following corollary to Proposition 3:

Corollary 2 Career concerns lower the cost of inducing the manager to take the standard action; that is, $\sigma_{1} \leq \sigma_{2}$ for any given level of discretion of $l$ and reputation $\theta$. Moreover, if the return to reputation-building is positive (negative), then career concerns make it relatively less (more) costly to induce the manager to take information-intensive actions. That is, $\theta \beta_{1}-\sigma_{1} \leq(>) 0$.

If $u_{2}(\theta)$ is convex (concave) in $\theta$, then $\theta u_{2}(1)-u_{2}(\theta) \geq(<) 0 .{ }^{12}$ A direct implication is:

Lemma 2 The return to reputation-building is positive (negative), when the manager's second-period payoff, $u_{2}(\theta)$, is convex (concave) in his second-period reputation.

Corollary 2 and Lemma 2 together imply that if increases in the manager's reputation have increasing marginal benefits, then the manager has a strong incentive to distinguish himself as a capable decisionmaker. $u_{2}(\theta)$ is convex if discretion increases rapidly as the manager's reputation improves, and if the increase in discretion is accompanied by large increases in both explicit compensation and private benefits, as is the case when $b(\cdot)$ is convex. To get some sense of when $u_{2}(\theta)$ is convex, recall that $v(\cdot)$ is a measure of the severity of the conflict of interests. $v$ is strictly increasing, allowing us to rewrite equation $(7)$ as $l_{2}(\theta)=v^{-1}(\theta-R)$. A direct implication of the preceding equation is that $l_{2}(\theta)$ is convex if and only if $v(\cdot)$ is concave. Intuitively, discretion increases rapidly as the manager's reputation improves only if the conflict of interests does not worsen too rapidly as the manager gains greater control. A sufficient (though not necessary) condition for the convexity of $u_{2}(\theta)$ is that $l_{2}(\theta)$ and $F(\cdot)$ be convex. The fact that $v(\cdot)=b^{\prime}(\cdot) / f(\cdot)$ is increasing and $F(\cdot)$ is convex, implies that $b(\cdot)$ is convex as well. Intuitively, if discretion and private benefits are convex in the manager's reputation, then $u_{2}(\theta)$ is convex as well. An example for such a situation arises when "stars" in the market are rewarded disproportionately relative to managers with average reputations. Conversely, if $u_{2}(\theta)$ is concave, the market disproportionately punishes weak performers, and managers have an incentive to take conservative actions in order to avoid placing their reputational capital at risk.

\footnotetext{
${ }^{12}$ When $u_{2}(\cdot)$ is linear, $\theta u_{2}(1)-u_{2}(\theta)=0$. I.e., when $u_{2}(\cdot)$ grows more (i.e. is convex) or less (i.e. is concave) than linearly, than $\theta u_{2}(1)-u_{2}(\theta) \geq(<) 0$.
} 


\subsection{Career Concerns and the Allocation of Authority}

Substituting the manager's best response, $a_{1}^{*}$, given in Proposition 3, into the profit function (2) results in the first-period maximization problem for the principal:

$$
\max _{l_{1} \in[0,1]} V_{1}\left(l_{1}\right)=R+(\theta-R) F\left(l_{1}\right)-\left(\theta \beta_{1}-\sigma_{1}\right) F\left(l_{1}\right)-\sigma_{1} .
$$

The profit function is similar to that in the previous section (equation (6)). One important difference is the additional term, $\left(\theta \beta_{1}-\sigma_{1}\right) F\left(l_{1}\right)$. As discussed above, $\theta \beta_{1}-\sigma_{1}$ represents the cost of implementing information-intensive actions relative to the standard action, while $F\left(l_{1}\right)$ is the probability that the manager takes such an action. As this cost increases, the marginal benefit of granting discretion decreases.

From Corollary 2, we know that the relative cost of implementing information-intensive actions depends on the return to reputation-building. Let $l_{1}(\theta)$ be the optimal level of discretion in the first period, and recall that $l_{2}(\theta)$ is the optimal level in the second period (and equals the optimal level of discretion in the static model). We have the following proposition:

Proposition 4 If the return to reputation-building is positive, then for any level of reputation $\theta$, the manager receives a higher level of discretion in the first period relative to the second period, i.e., $l_{1}(\theta) \geq l_{2}(\theta)$. If the return is negative, then there exists a value $\delta^{*} \geq \frac{1}{2}$, such that if the discount factor is $\delta \leq \delta^{*}$, then the level of discretion is lower in the first period, i.e., $l_{1}(\theta) \leq l_{2}(\theta)$.

When the return to reputation-building is positive, it is cheaper for the principal to induce the manager to use his discretion productively, and the principal grants the manager greater authority. Conversely, when the return to reputation-building is negative, the explicit incentives necessary to make the manager use his discretion productively become relatively more costly (although the absolute cost of incentives may go down). The principal responds by reducing the manager's authority.

However, when the discount factor is sufficiently high, there may be cases in which the optimal level of discretion is higher, although the returns to reputation building are negative. Notice from equation (9), that the incentive payment for the standard action, $\sigma_{1}$, is zero when $b\left(l_{1}\right)<\delta u_{2}(\theta)$ (since incentive payments cannot be negative). It is optimal for the principal to increase $l_{1}$ as long as $\sigma_{1}=0 .{ }^{13}$ Therefore, if the level of discretion at which $\sigma_{1}$ becomes positive is sufficiently large,

${ }^{13}$ To be precise, it is optimal to do so unless $\theta-R+\theta \beta_{1}<0$, in which case the value of the manager's information is lower than the cost of inducing the manager to utilize it (see equation (13)). In this case, the optimal level of discretion is zero. 
then $l_{1}(\theta) \geq l_{2}(\theta)$ regardless of the returns to reputation-building. Intuitively, it is possible that the positive career concerns (the lower absolute cost of implementing the standard action) outweigh the negative career concerns (the higher relative cost of implementing information-intensive actions). ${ }^{14}$

Differentiating $V_{1}\left(l_{1}\right)$ makes the relationship between authority and the returns to reputationbuilding particularly clear. Assuming that the incentive payments are strictly positive and substituting equations (11) and (12) for $\sigma_{1}$ and $\theta \beta_{1}$, we obtain the following first order condition:

$$
(\theta-R)=v\left(l_{1}\right)-\delta\left(\theta u_{2}(1)-u_{2}(\theta)\right)
$$

Equation (14) is the dynamic analogue to equation (7). At the optimal level of discretion, the expected value of the manager's information equals exactly the value required to compensate the principal for the marginal cost of incentives; this value is $v\left(l_{1}\right)$ adjusted for the returns to reputation-building.

The key result in this section is that while implicit incentives discourage purely opportunistic behavior, it may actually become more costly to encourage the manager to take actions that are risky in the sense that the returns depend on the quality of the manager's information - relative to the cost of inducing managers to take a conservative action. This situation arises if the expected returns to building a reputation are lower than the benefits of simply preserving a given reputation. Specifically, if expected future compensation of the manager is concave in his reputation, the manager has an incentive to behave conservatively. The principal optimally responds to such conservatism by limiting the discretion of the manager relative to the static model. On the other hand, if the returns to building a reputation are large, the manager has a strong incentive to use his discretion productively and is allocated greater authority.

\section{Repeated INTERACTION}

The success or failure of a project is revealing about a decision-maker's ability only in proportion to the scope of his or her authority. For instance, the performance of a division indicates little about the decision-making capability of the division manager if he is simply carrying out the orders of

\footnotetext{
${ }^{14}$ The condition on $\delta$ in the second part of Proposition 4 ensures that the corner, where $b\left(l_{1}\right)=\delta u_{2}(\theta)$ is less than $l_{2}(\theta)$, so that the relative cost of incentives determines the level of discretion. The incentive payment, $\sigma_{1}$, reflects the fact that if the manager abuses his discretion, he suffers a complete loss of his reputational capital. If there is some noise in the profit function, the severity of the market's punishment for poor performance decreases, lowering the cost of pursuing private benefits and increasing $\sigma_{1}$. In this scenario, it can be shown that conditions on the discount factor are not necessary to obtain the result in Proposition 4.
} 
the headquarters. In the previous section, if the principal grants the manager a first-period level of discretion, $l_{1}$, then with probability $F\left(l_{1}\right)$ the manager's type is revealed to the market. Thus, future lenders or employers are better able to assess the ability of managers who are given greater discretion in past relationships. However, the informational benefits of discretion are ignored by current lenders and employers if they do not anticipate future interactions with the manager. The analysis in this section shows that when the relationship extends over multiple periods, the principal internalizes the informational externality present early in the relationship, and increases discretion relative to a short-term relationship.

We proceed by extending our analysis to the natural case where the relationship may span both periods, but assume that the principal can only commit to single-period contracts. ${ }^{15}$ If the manager is revealed to be uninformed at the end of the first period $(\hat{\theta}=0)$, the principal rationally chooses to hire a new manager, whose reputation is given by $\theta$. The notation for all variables is the same as in the previous section, except a superscript $R$ is added to indicate repeated interaction.

Absent commitment, the second-period contract must maximize the principal's second-period profit and is therefore $\left\{b\left(l_{2}^{R}(\hat{\theta})\right) / \hat{\theta}, b\left(l_{2}^{R}(\hat{\theta})\right),\left[0, l_{2}^{R}(\hat{\theta})\right]\right\}$, where $\hat{\theta}$ equals either the updated reputation of the existing manager or equals $\theta$ when the principal hires a new manager. This contract yields the principal an expected utility of $V\left(l_{2}^{R}(\hat{\theta})\right)$, as given by equation (6) and is the principal's expected utility in the static model. Simplifying notation, we define $V_{2}(\hat{\theta}) \equiv V\left(l_{2}^{R}(\hat{\theta})\right)$. The principal's minimum level of utility in the second period is $V_{2}(\theta)$ since she can always hire a manager with reputation $\theta$.

Proposition 3 applies here as well, implying that the optimal first period contract is of the form $\left\{\beta_{1}^{R}, \sigma_{1}^{R},\left[0, l_{1}^{R}\right]\right\}$ and the first-period incentive payments are given by equations (9) and (10). The equilibrium incentive payments induce the manager to act on his information whenever he receives a signal $s_{1} \in\left[0, l_{1}^{R}\right]$ and take the standard action otherwise. The manager receives such a signal with probability $F\left(l_{1}^{R}\right)$ and with probability $\theta$ turns out to be the high type. In this case, the principal rehires the manager and receives $V_{2}(1)-V_{2}(\theta)$ of additional utility over the baseline level of $V_{2}(\theta)$.

Let $\Pi\left(l_{1}^{R}\right)$ be the sum of the principal's first and second-period expected payoffs when she offers the manager a first-period level of discretion $l_{1}^{R}$. $\Pi\left(l_{1}^{R}\right)=V_{1}\left(l_{1}^{R}\right)+\delta E\left[V_{2}(\hat{\theta})\right]$, where $V_{1}\left(l_{1}^{R}\right)$ is the

\footnotetext{
${ }^{15}$ In Englmaier et al. (2010) we analyze long-term contracts. We show that when the principal can commit to long-term contracts, she counters the conservative bias of managers by raising the future utility of successful managers, $u_{2}(1)$, by rewarding them with greater authority and incentive payments than would prevail in the market otherwise. Offering greater compensation in the second period has no first order impact on the principal's second-period profit. However, increasing the manager's second period utility, $u_{2}(1)$, has a first order impact on the principal's profit in the first period because it lowers the incentive payments necessary to induce information-intensive actions.
} 
principal's first-period expected utility as given by equation (13). Given our analysis of the second period hiring decisions, the principal chooses the first-period level of discretion to maximize:

$$
\max _{l_{1}^{R} \in[0,1]} \Pi\left(l_{1}^{R}\right)=V_{1}\left(l_{1}^{R}\right)+\delta V_{2}(\theta)+\delta \theta\left[V_{2}(1)-V_{2}(\theta)\right] F\left(l_{1}^{R}\right)
$$

The last term in the preceding equation, $\delta \theta\left[V_{2}(1)-V_{2}(\theta)\right] F\left(l_{1}^{R}\right)$, captures the informational benefit of giving the manager discretion early in the relationship. The greater the first-period level of discretion, $l_{1}^{R}$, the greater the likelihood that the principal learns about the manager's ability and makes the optimal hiring decision in the second period. Beyond this additional effect, the principal faces the identical tradeoffs as in the previous section as $\delta V_{2}(\theta)$ does not depend on the first-period discretion, and thus has no impact on the level of discretion. It immediately follows that the optimal level of discretion must be weakly greater than in a short-term relationship. Let $l_{1}^{R}(\theta)$ be the optimal level of discretion in the first period and $\left(\beta_{1}^{R}(\theta), \sigma_{1}^{R}(\theta)\right)$ be the associated compensation package. Recall that $l_{1}(\theta)$ is the optimal first-period discretion when only short-term relationships are possible, and let $\left(\beta_{1}(\theta), \sigma_{1}(\theta)\right)$ denote the optimal incentives for this case. We have established the following proposition:

Proposition 5 If the horizon of the relationship is extended, then the optimal level of discretion and the corresponding incentive payments increase. Equivalently, $l_{1}^{R}(\theta) \geq l_{1}(\theta), \beta_{1}^{R}(\theta) \geq \beta_{1}(\theta)$, and $\sigma_{1}^{R}(\theta) \geq \sigma_{1}(\theta)$.

Whereas in a short-lived relationship the informational benefit of discretion accrues to the future employers and lenders and is ignored by the principal, the principal internalizes this benefit and chooses a higher level of discretion in a long-term relationship. Throughout we have assumed that $\theta>R$. However, the informational benefit of discretion may cause the principal to delegate some control even if $\theta<R$. That is, even if the manager's reputation is so low that the net expected surplus generated from his decisions is negative in a static setting, the principal may give the manager decision-making rights as a way of screening for informed managers.

\section{Related Literature and Empirical Research}

The static trade-off between information and control has been discussed extensively in the literature. The delegation problem was initially analyzed by Holmström (1984) while Jensen and Meckling (1992) focussed on strategies how organizations resolve the associated problems. Harris and Raviv (1996) model the capital budgeting process of firms and show that when division managers 
are more informed about the productivity of capital and have a preference for large investments, the optimal mechanism involves spending limits. Several papers have explored the complementarity between incentives and control. Prendergast (2002) shows that managers receive both greater discretion and stronger incentives in environments characterized by complexity and uncertainty due to their information advantage in such environments. Holmström and Milgrom (1991) also establish the complementarity between incentives and control, although for reasons unrelated to any information advantage of managers. In their model, workers given greater freedom to allocate time to personal activities must also receive stronger incentives to behave productively in work-related activities.

Aghion and Bolton (1992) consider a problem where investors not only give the entrepreneur monetary incentives, but also retain control rights. The inability to write complete contracts and the fact that neither party has the incentive to take the action that maximizes social surplus in all circumstances, makes it efficient to vary control rights across contingencies. In our model, while the principal always has the incentive to choose the first-best action, the agent has an informational advantage. Control considerations arise due to the information asymmetry and not the incompleteness of contracts (though limiting the set of feasible contracts aggravates the problem).

A more recent and related treatment is Alonso and Matouschek (2008), though they assume that the principal is unable to commit to contingent transfers. They show that the contracting problem of a principal who faces an informed but biased agent reduces to a delegation problem in which the principal commits to a set of decisions from which the agent chooses his preferred one. Krishna and Morgan (2008) study optimal contracting in a model with an uninformed principal and an informed agent where the principal can commit to a payment scheme but retains ultimate decision-making authority. They show that the optimal contract never induces the agent to fully reveal his information. Similar to our analysis, both in Alonso and Matouschek (2008) and Krishna and Morgan (2008) the results depend on the degree of conflict of interests between the principal and the agent.

Most papers on delegation use a similar setup: (1) an organization consisting of a principal and an agent must make a decision, (2) the agent has private information relevant for a jointly optimal decision, and (3) the principal's and agent's individual preferences over decisions diverge. The contracting assumptions with respect to decision and transfer rules, however, vary considerably. In one extreme, Crawford and Sobel (1982) assume that the principal cannot commit to any decision or transfer rule. In the other extreme, Krishna and Morgan (2008) assume that the principal can write fully contingent decision and compensation contracts. The rest of the literature falls between these two extremes. Dessein (2002) is close to Crawford and Sobel in that it also prohibits both transfer and 
decision rules but allows the complete set of decision rights to be assigned to the principal or the agent. Holmström (1984) and Alonso and Matouschek (2008) allow for decision rules but prohibit transfer rules. Our paper can be viewed as somewhat orthogonal to those two papers: we allow transfer rules but prohibit decision rules. We say "somewhat orthogonal" because while the agent cannot commit to take a specific action in response to his information, the principal can commit to withhold a set of actions from the agent. In this respect, our decision rights assignment is similar to Dessein (2002), except it is continuous.

Our result on the dynamic aspect of granting authority to a manager, namely that it may be profitable to grant "excessive" authority to an agent early on in a relation, has been discussed in the literature, though in the context of eliciting information on whether or not the agent is "trustworthy" and without considering a role for explicit monetary incentives. Aghion, Dewatripont, and Rey (2004) introduce the notion of transferable control, defined as a situation where the principal can transfer control to the agent but cannot commit herself to do so and use this notion to study the extent to which control transfers allow an agent to reveal information regarding his willingness to cooperate with the principal in the future. They show that, when control is transferable but not contractible, it can be optimal to transfer control unconditionally and learn instead from the way in which the agent exercises control. Boot, Greenbaum, and Thakor (1993) explain the use of legally unenforceable, discretionary financial contracts in circumstances where legally enforceable contracts are feasible and argue that discretionary contracts foster the development of reputation. Finally, Ichino and Muehlheusser (2008) provide a result very similar to ours with regard to the monitoring decisions of a principal. They show that a principal may refrain from monitoring early in a relationship to test whether an agent is the type that exploits the possibility to misbehave.

Kaarbøe and Olsen (2006) analyze how the strength of explicit incentives evolves over time, though in a context unrelated to a manager's use of information and managerial conservatism. Like our paper, they establish that career concerns may result in stronger explicit incentives early in a manager's career. However, Kaarbøe and Olsen (2006) argue in a multitasking framework that career concerns may provide incentives to engage only in some tasks, making it necessary to provide counterbalancing explicit incentives for other tasks.

Several papers have studied how career concerns affect both managerial behavior and job design. While Fama (1980) argues that the labor market plays an important role in disciplining managers, Holmström (1999) and Holmström and Ricart i Costa (1986) show that while this is correct in some circumstances, career concerns can actually aggravate conflicts of interests. Similar to our 
study, they show that career concerns may make it harder to motivate risk taking as managers may underinvest in risky, but profitable, projects to preserve their reputational capital. In a related vein, Scharfstein and Stein (1990) and Zwiebel (1995) show that managers have an incentive to mimic other managers, ignoring substantive private information, in order to avoid "standing out" and to protect their reputations. Ely and Välimäki (2003) even show that an agent's desire to preserve his reputation can in fact lead to the loss of the entire surplus in a transaction.

Several studies provide empirical support for our results. Magnan and St-Onge (1997) study executive compensation in the commercial banking industry and find a statistically significant correlation between measures of managerial discretion and the sensitivity of compensation to performance. A more recent analysis of the same industry by Nagar (2002) shows that high growth and innovative banks grant their branch managers greater authority and stronger incentives relative to their peers at stable banks. This suggests that branch managers receive greater authority and incentives when their tasks are more information intensive. Finally, it is natural to expect that stricter controls are placed on managers in situations where there is a wide divergence of interests. In the context of corporate governance, the severity of the conflict of interests, $v$, is in part determined by the quality of institutions which protect investor rights, lowering the returns to self-dealing by dominant shareholders and managers. In this vein, La Porta, Lopez-de Silanes, Shleifer, and Vishny (1997) and Shleifer and Vishny (1997) argue that in countries with weaker protections, there is a bias away from forms of finance which result in the separation of ownership and control.

Chevalier and Ellison (1999) show that termination probabilities for young mutual fund managers increase steeply with underperformance, but are fairly insensitive to overperformance. In the language of our analysis, there is a negative return to reputation-building. Consistent with the incentives to avoid "standing out", the authors find that young managers hold more conventional portfolios. Regarding the use of incentives, Dass, Massa, and Patgiri (2008) establish an empirical relation between stronger contractual incentives and a reduction in herd behavior among fund managers. Finally, Gibbons and Murphy (1992) and Kahn and Sherer (1990) study the relation between implicit and explicit incentives as tenure increases. Gibbons and Murphy (1992) find cross-sectional evidence for their above mentioned result, that chief executives receive stronger explicit incentives as they approach retirement age whereas Kahn and Sherer (1990) analyze longitudinal data from a single firm and find, in line with our predictions, that bonus payments of high-level managers are actually less sensitive to performance as tenure increases. However, both Gibbons and Murphy (1992) and Kahn and Sherer (1990) measure the average sensitivity of pay to performance, whereas our theory suggests that the 
sensitivity of pay to performance varies with the level of performance. The average sensitivity of pay is a function of both the incentive payments for moderate, $\sigma$, and excellent performance, $\beta$. Since $\sigma$ always increases with tenure, the average sensitivity of pay to performance decreases with tenure only if $\beta$ decreases with tenure - which happens only if there are negative returns to reputation-building. This suggests that in the sample of Kahn and Sherer, high-level managers with low seniority must be given strong monetary incentives to counter implicit incentives to "play it safe". On the other hand, our analysis suggests that in Gibbons and Murphy's sample of CEO's, the rising average sensitivity of pay to performance with tenure is largely due to changes in $\sigma$. This would indicate that the prevention of blatant abuse of authority is a first-order consideration in the design of compensation for the executives studied by Gibbons and Murphy.

\section{Conclusion}

In this paper, we analyze the design of compensation schemes and the allocation of authority in a dynamic principal-agent framework. We show that a manager's discretion is increasing in the value of his information and in the quality of his reputation, and decreasing in the severity of the conflict of interests. Moreover, managers given greater discretion must receive larger monetary incentives to align their interests with those of the principal. Our analysis implies that talented decision-makers are given extensive control rights and receive generous incentive compensation.

With this intuitive interrelationship between information, authority, and incentives as a baseline, we explore the role of career concerns. Career concerns lower the cost of explicit incentives necessary to discourage clear forms of opportunism, since managers have an incentive to preserve their reputation. However, in an effort to avoid negative inferences about their ability, managers may make overly conservative decisions, neglecting their own information. Implicit incentives may thus increase the explicit incentives necessary to induce risk-taking. In such a scenario, the principal reduces managerial discretion to economize on the increased cost of incentives.

These results link our model to theories of managerial conservatism in which career concerns cause managers to undertake less innovative projects, despite their knowledge that such investments are inferior. We show that a principal optimally preempts such behavior by both strengthening incentives and limiting managerial authority. The costs of managerial conservatism thus include not only those cases in which decision-makers choose to ignore valuable information, but also those cases in which decision-makers are forced to ignore information as a result of the centralization of decision-making. 
The allocation of control changes as the horizon of the relationship changes. Since it is easier to infer the ability of managers if they have more authority, discretion serves as a screening device. When the principal expects to engage in a long-term relationship with a manager, she internalizes this informational benefit and gives the manager greater authority.

\section{A Proofs}

\section{A.1 Proof of Lemma 1}

Suppose $C=\{\beta, \sigma, \mathcal{A}\}$ maximizes the principal's profit. To establish the Lemma, it suffices to show that there is an interval $[k, l]$ such that the modified contract $\tilde{C}=\{\beta, \sigma,[k, l]\}$ satisfies $V(\tilde{C})=V(C)$ and $a^{*}(s, \tilde{C})=s$ for $s \in[k, l]$ and $a^{*}=\bar{a}$ otherwise. Let $\overline{\mathcal{A}}=\left\{s: a^{*}(s, C)=s\right\} . \overline{\mathcal{A}}$ is the set of signals at which the manager takes the action corresponding to his signal. If $\operatorname{Pr}[\omega \in \overline{\mathcal{A}}]=0$, then allowing the manager discretion has no benefit for the principal. Therefore, restricting the manager to $\{\bar{a}\}$ or $\{\bar{a}, 0\}$ achieves the same level of profit. In this case, the degenerate interval $[k, l]=[0,0]$ satisfies the proposition.

Suppose that $\operatorname{Pr}[\omega \in \overline{\mathcal{A}}]>0$, and let $l=\max \mathcal{A}$ (recall that $\mathcal{A}$ is compact so that $l$ is well-defined). Using the agent's expected payoff from taking an action (see equation (1)), it must be the case that $\theta \beta+b(s) \geq \max \{\sigma, b(l)\}$ for any signal $s \in \overline{\mathcal{A}}$. It follows that for any signal $z$ greater than $s$, $\theta \beta+b(z) \geq \max \{\sigma, b(l)\}$ and $a^{*}(z, C)=z$, provided $z$ is in $\mathcal{A}$. In particular, this argument implies that $l \in \overline{\mathcal{A}}$.

Now suppose that the principal offers the manager, the revised contract $J=\{\beta, \sigma, \overline{\mathcal{A}}\}$. Since $l \in \overline{\mathcal{A}}$, the action that maximizes private benefit is unchanged under the new contract. In addition, the payoff to the standard action remains unchanged. Since the revised contract contains exactly those actions which the manager chooses to take under the original contract, and since the payoffs from taking those actions are unchanged, $a^{*}(s, J)=a^{*}(s, C)$ for all $s \in[0,1]$. Therefore, $V(C)=V(J)$.

Let $k=\min \overline{\mathcal{A}}$, and let $\mathcal{Z}=[k, l]-\overline{\mathcal{A}}$. $\mathcal{Z}$ is the set of actions between $k$ and $l$ which the manager cannot take. Since $a^{*}(k, J)=k$, if the manager receives a signal $z>k$ in $\mathcal{Z}$, he would choose $a=z$ if the action were allowed. Given that the contract $J$ maximizes the principal's profit and $\operatorname{Pr}[\omega \in \overline{\mathcal{A}}]>0$, the payoff for the principal when the manager takes the action corresponding to his signal is higher than if the manager chooses the standard action. In particular, it must be the case that $\theta(1-\beta) \geq R-\sigma$. If not, the principal could achieve a higher profit by completely restricting the manager to the standard action. Therefore, if the manager receives a signal $z$ in $\mathcal{Z}$, the principal would 
be better off if the manager were allowed to take the action corresponding to the signal. Therefore, $V(\beta, \sigma,[k, l]) \geq V(J)$. The optimality of $J$ implies that $V(\beta, \sigma,[k, l])=V(J)$.

Let $\tilde{C}=\{\beta, \sigma,[k, l]\}$. We have already shown that $a^{*}(s, \tilde{C})=s$ for $s \in[k, l]$. It remains to show that $a^{*}(s, \tilde{C})=\bar{a}$ otherwise. For $s \notin[k, l], a^{*}(s, \tilde{C})=\bar{a}$ if $\sigma \geq b(l)$. Under the assumption that $R>b(1) \geq b(l)$, it always pays for the principal to increase social surplus and make the standard action incentive compatible. Therefore, the optimality of $C$ implies that $a^{*}(s, \tilde{C})=\bar{a}$ if $s \notin[k, l]$.

\section{A.2 Proof of Proposition 1}

From Lemma 1, we can restrict attention to contracts for which $a^{*}(s)=s$ for $s \in[k, l]$, and $a^{*}(s)=\bar{a}$, otherwise. From the manager's payoff function as given by equation (1), it follows that if $a^{*}(s)=s$ for $s \in[k, l]$, then $\theta \beta+b(s) \geq \sigma$ for $s \in[k, l]$. In addition, if $a^{*}(s)=\bar{a}$ for $s \notin[k, l]$, then $\sigma \geq b(l)$. These two inequalities together imply that $\theta \beta \geq b(l)-b(k)$.

Let $\Delta F=F(l)-F(k)$. The principal's expected profit from $\{\beta, \sigma,[k, l]\}$ is

$$
\begin{aligned}
V(\beta, \sigma,[k, l]) & =(1-\beta) \theta \operatorname{Pr}\left[a^{*}(s)=s\right]+(R-\sigma) \operatorname{Pr}\left[a^{*}(s)=\bar{a}\right] \\
& =(1-\beta) \theta(\Delta F)+(R-\sigma)(1-\Delta F)
\end{aligned}
$$

Note that $(1-\beta) \theta \geq R-\sigma$; otherwise, the principal could increase her profit by reducing the discretion of the manager, violating the optimality of the contract.

Choose $z$ such that $b(z)=b(l)-b(k)$ (since $b(0)=0$, continuity ensures that such a point exists). Let $G=F \circ b^{-1}$. The assumption that $v$ is increasing, ensures that $G$ is concave. In particular, for any $h$ and $w, G(h) \geq G(w+h)-G(w)$. Letting $h=b(z)$ and $w=b(k)$, we have that $F(z)=G(h) \geq$ $G(w+h)-G(w)=\Delta F$.

Consider the revised contract $\left\{\beta, \sigma^{\prime},[0, z]\right\}$ where $\sigma^{\prime}=b(z)$, and let $\hat{a}^{*}(s)$ be the manager's new best response function. Since $\theta \beta \geq b(l)-b(k)=b(z)=\sigma^{\prime}$, the manager will choose to utilize his information whenever possible, and is indifferent between the standard action and the action that maximizes his private benefit, $z$. Therefore, $\hat{a}^{*}(s)=s$ for $s \in[0, z]$, and $\hat{a}^{*}(s)=\bar{a}$ otherwise. The principal's expected profit from this contract is $V\left(\beta, \sigma^{\prime},[0, z]\right)=(1-\beta) \theta F(z)+\left(R-\sigma^{\prime}\right)(1-F(z))$.

If $z<l$, then $\sigma^{\prime}<\sigma$. This inequality, together with inequalities, $F(z) \geq \Delta F$ and $(1-\beta) \theta \geq R-\sigma$, imply that $V\left(\beta, \sigma^{\prime},[0, z]\right)>V(\beta, \sigma,[k, l])$, contradicting the optimality of $\{\beta, \sigma,[k, l]\}$. Therefore, $k=0$ and $z=l$, which completes the proof. 


\section{A.3 Proof of Proposition 2}

Let $V(l)=(\theta-R) F(l)-b(l)+R$. Then $V^{\prime}(l)=f(l)[(\theta-R)-v(l)]$. Recall that $v$ is assumed to be strictly increasing. This is sufficient to ensure that the second order conditions are satisfied and that $v(0)<(\theta-R)<v(1) .{ }^{16}$ In this case there is a unique $l^{*}$ such that $\theta-R=v\left(l^{*}\right)$. Since $V$ is strictly increasing for $l<l^{*}$ and decreasing for $l>l^{*}, l^{*}$ is the unique maximum, establishing the first statement of the Proposition. Finally, it is easily verified that $l^{*}$ is increasing in $\theta$, and decreasing in $R$ and $v$.

\section{A.4 Proof of Proposition 3}

Suppose that the principal offers the manager a first-period contract $C=\left\{\beta_{1}, \sigma_{1}, \mathcal{A}_{1}\right\}$ and that the markets beliefs in the second period are $\hat{\theta}\left(a_{1}, \pi_{1}\right)$. In addition, recall that the manager's equilibrium payoff in the second period is $u_{2}\left(\hat{\theta}\left(a_{1}, \pi_{1}\right)\right)$. The manager's expected utility from taking action $a_{1}$ in the first period, conditional on observing signal $s_{1}$, is

$$
E\left[u_{1}+\delta u_{2} \mid s_{1}, C\right]= \begin{cases}\theta \beta_{1}+b\left(s_{1}\right)+\theta \delta u_{2}\left(\hat{\theta}\left(s_{1}, 1\right)\right)+(1-\theta) \delta u_{2}\left(\hat{\theta}\left(s_{1}, 0\right)\right) & \text { if } a_{1}=s_{1} \\ \sigma_{1}+\delta u_{2}(\hat{\theta}(\bar{a}, R)) & \text { if } a_{1}=\bar{a} \\ b\left(a_{1}\right)+\delta u_{2}\left(\hat{\theta}\left(a_{1}, 0\right)\right) & \text { otherwise } .\end{cases}
$$

We first show that for any contract, $C$, there is an equilibrium in the continuation game such that the manager's best response to $C$ is always to choose one of two actions: the action corresponding to his information and either the standard action or the action that maximizes private benefits.

If $\sigma_{1}+\delta u_{2}(\theta) \geq b\left(l_{1}\right)$, consider the following best response and beliefs:

$$
a_{1}^{*}=\left\{\begin{array}{ll}
s_{1} & \text { if } s_{1} \in \overline{\mathcal{A}} \\
\bar{a} & \text { otherwise }
\end{array} \text { and } \hat{\theta}= \begin{cases}1 & \text { if } \pi_{1}=1 \\
\theta & \text { if } \pi_{1}=R \\
0 & \text { if } \pi_{1}=0\end{cases}\right.
$$

where $\overline{\mathcal{A}}=\left\{s_{1} \in \mathcal{A}_{1}: \theta \beta_{1}+\delta \theta u_{2}(1)+b\left(s_{1}\right) \geq \sigma_{1}+\delta u_{2}(\theta)\right\}$. Given these beliefs, it follows from the payoff function (15) and the definition of $\overline{\mathcal{A}}$ that $a_{1}^{*}$ is indeed a best response for the manager. Conversely, we can show that $\hat{\theta}$ is consistent with Bayes rule whenever applicable. Given $a_{1}^{*}$, any action $a_{1} \in \overline{\mathcal{A}}$ is taken if and only if $s_{1}=a_{1}$. It follows that conditional on observing the manager take any

\footnotetext{
${ }^{16}$ If $(\theta-R) \leq v(0)$ then $V$ is strictly decreasing over the entire interval [0,1], and $l^{*}=0$ is the unique maximum. Similarly, if $(\theta-R) \geq v(1)$, then $V$ is strictly increasing, and $l^{*}=1$ is the maximum.
} 
such action, updated beliefs are $\hat{\theta}=\pi_{1}, \pi_{1} \in\{0,1\}$, since high types generate a profit of 1 with a probability of 1 and low types generate a profit of 0 with a probability of 1 . No action $a_{1} \in \mathcal{A}_{1}-\overline{\mathcal{A}}$ is ever taken, hence the conditional probability can be arbitrarily set as $\hat{\theta}\left(a_{1}, \pi_{1}\right)=\pi_{1}, \pi_{1} \in\{0,1\}$ as well. Finally, since the probability that the manager takes action $\bar{a}$ is independent of his type and since the profit generated from $\bar{a}$ is independent of his type as well, the inference when $a_{1}=\bar{a}$ remains unchanged. That is, $\hat{\theta}(\bar{a}, R)=\theta$.

If instead $\sigma_{1}+\delta u_{2}(\theta)<b\left(l_{1}\right)$, there is an equilibrium of the continuation game given by,

$$
a_{1}^{*}=\left\{\begin{array}{ll}
s_{1} & \text { if } s_{1} \in \overline{\mathcal{A}} \\
l_{1} & \text { otherwise }
\end{array} \text { and } \hat{\theta}= \begin{cases}1 & \text { if } \pi_{1}=1 \\
\theta & \text { if } \pi_{1}=R \\
\theta & \text { if } \pi_{1}=0, a_{1}=l_{1}, \text { and } \operatorname{Pr}\left[a_{1}^{*}=l_{1}\right]>0 \\
0 & \text { otherwise }\end{cases}\right.
$$

where $\overline{\mathcal{A}}=\left\{s_{1} \in \mathcal{A}_{1}: \theta \beta_{1}+\delta \theta u_{2}(1)+b\left(s_{1}\right) \geq b\left(l_{1}\right)+\delta u_{2}(\theta)\right\}$. Again, given the beliefs, the definition of $\overline{\mathcal{A}}$ and the payoff function (15), it is easy to verify that $a_{1}^{*}$ is a best response. Also, given the manager's behavior, any action $a_{1} \in \overline{\mathcal{A}}-\left\{l_{1}\right\}$ is taken if and only if $s_{1}=a_{1}$, and the conditional probability is therefore $\hat{\theta}\left(a_{1}, \pi_{1}\right)=\pi_{1}, \pi_{1} \in\{0,1\}$. No action $a_{1} \in \mathcal{A}_{1}-\overline{\mathcal{A}} \cup\left\{l_{1}\right\}$ is ever taken, and the conditional probability can be arbitrarily set as $\hat{\theta}\left(a_{1}, \pi_{1}\right)=\pi_{1}, \pi_{1} \in\{0,1\}$ as well. Action $l_{1}$ is either taken with a positive probability, in which case $\hat{\theta}\left(l_{1}, 1\right)=1$ and $\hat{\theta}\left(l_{1}, 0\right)=\theta$, or it is taken only when $s_{1}=l_{1}$, in which case $\hat{\theta}\left(l_{1}, 1\right)=1$ and $\hat{\theta}\left(l_{1}, 0\right)=0$. Finally, action $\bar{a}$ is never taken, and the conditional probability can be arbitrarily assigned the value $\theta$.

It follows that $\left(a_{1}^{*}, \hat{\theta}\right)$ is an equilibrium of the continuation game, given $C$. We can now analyze the principal's optimal choice of $C$ in light of this equilibrium. Given our assumption that $b(1)<R$, the principal always prefers to induce the manager to take the standard action rather than the action that maximizes his private benefit. Therefore, $\sigma_{1}$ is chosen to satisfy, $\sigma_{1}+\delta u_{2}(\theta) \geq b\left(l_{1}\right)$, and the equilibrium of the continuation game, given by (16), applies. The manager's expected payoff is therefore:

$$
E\left[u_{1}+\delta u_{2} \mid s_{1}, C\right]= \begin{cases}\theta \beta_{1}+b\left(s_{1}\right)+\theta \delta u_{2}(1) & \text { if } a_{1}=s_{1} \\ \sigma_{1}+\delta u_{2}(\theta) & \text { if } a_{1}=\bar{a} \\ b\left(a_{1}\right) & \text { otherwise } .\end{cases}
$$

The payoff from taking any given action differs by at most a constant from his payoffs in the static setting (equation (1)). Furthermore, the principal's profit function is unchanged and is given by equation (2). Therefore, Lemma 1 and Proposition 1, with minor modifications, apply in this context 
as well. It follows that the principal allows the manager to choose an action from a set of the form $\left[0, l_{1}\right]$.

It remains to characterize the principal's choice of $\beta_{1}$ and $\sigma_{1}$. Given the manager's expected payoffs, to induce him to choose $\bar{a}$ when $s_{1} \notin\left[0, l_{1}\right]$ and to take the action corresponding to his signal when $s_{1} \in\left[0, l_{1}\right]$, it must be the case that:

$$
\begin{aligned}
\sigma_{1}+\delta u_{2}(\theta) & \geq b\left(l_{1}\right) \\
\theta \beta_{1}+\theta \delta u_{2}(1)+b\left(a_{1}\right) & \geq \sigma_{1}+\delta u_{2}(\theta) \quad \text { for } a_{1} \in\left[0, l_{1}\right] .
\end{aligned}
$$

In addition to these conditions, the optimal contract must satisfy the following nonnegativity conditions: $\sigma_{1} \geq 0$ and $\beta_{1} \geq 0$. At the optimum, either equation (17) binds or $\sigma_{1}=0$. Similarly, either equation (18) binds or $\beta_{1}=0$. These conditions reduce to equations (9) and (10), completing the proof.

\section{A.5 Proof of Proposition 4}

Adding and subtracting $b\left(l_{1}\right)$ from the principal's profit function given in (13), the function can be re-written as $V_{1}\left(l_{1}\right)=V_{2}\left(l_{1}\right)+\left(\sigma_{1}-\theta \beta_{1}\right) F\left(l_{1}\right)+b\left(l_{1}\right)-\sigma_{1}$, where $V_{2}$ is the principal's profit function in the second period and is equal to the profit function in the static setting as given by equation (6). Recall that $\sigma_{1}=\max \left\{b\left(l_{1}\right)-\delta u_{2}(\theta), 0\right\}$ and $\theta \beta_{1}=\max \left\{\sigma_{1}+\delta\left(u_{2}(\theta)-\theta u_{2}(1)\right), 0\right\}$, and note that $-\max (z)=\min (-z)$ for any function $z$. We can write $\sigma_{1}-\theta \beta_{1}=\sigma_{1}+\min \left\{\delta\left(\theta u_{2}(1)-u_{2}(\theta)\right)-\right.$ $\left.\sigma_{1}, 0\right\}=\min \left\{\delta\left(\theta u_{2}(1)-u_{2}(\theta)\right), \sigma_{1}\right\}$. Notice that $\delta\left(\theta u_{2}(1)-u_{2}(\theta)\right)$ is independent of $l_{1}$ and $\sigma_{1}$ is weakly increasing in $l_{1} . \sigma_{1}$ is non-negative, and if reputation-building has positive expected return, $\delta\left(\theta u_{2}(1)-u_{2}(\theta)\right)$ is non-negative as well. Therefore, $\left(\sigma_{1}-\theta \beta_{1}\right) F\left(l_{1}\right)$ is a weakly increasing function of $l_{1}$. Using the expression for $\sigma_{1}, b\left(l_{1}\right)-\sigma_{1}=b\left(l_{1}\right)+\min \left\{\delta u_{2}(\theta)-b\left(l_{1}\right), 0\right\}=\min \left\{\delta u_{2}(\theta), b\left(l_{1}\right)\right\}$, which is also weakly increasing in $l_{1}$. Since $V_{1}\left(l_{1}\right)=V_{2}\left(l_{2}\right)+g\left(l_{1}\right)$, where $g(\cdot)$ is a weakly increasing function, it must be the case that the level of discretion that maximizes $V_{1}$ is greater than the level of discretion that maximizes $V_{2}$. Equivalently, $l_{1}(\theta) \geq l_{2}(\theta)$.

Assume the expected return to reputation-building is negative. Then, using the expression derived above, $\left(\sigma_{1}-\theta \beta_{1}\right)=\delta\left(\theta u_{2}(1)-u_{2}(\theta)\right)$, which is negative and independent of $l_{1}$. It follows that $\left(\sigma_{1}-\theta \beta_{1}\right) F\left(l_{1}\right)$ is a weakly decreasing function of $l_{1}$. Define $l_{\sigma}$ to be the value of $l_{1}$ at which $\sigma_{1}$ starts taking positive values. That is, $b\left(l_{\sigma}\right)=\delta u_{2}(\theta)$. On the interval $\left[l_{\sigma}, 1\right], b\left(l_{1}\right)-\sigma_{1}=\min \left\{\delta u_{2}(\theta), b\left(l_{1}\right)\right\}=$ $\delta u_{2}(\theta)$, which is constant in $l_{1}$. It follows that for $l_{1} \geq l_{\sigma}, V_{1}\left(l_{1}\right)=V_{2}\left(l_{1}\right)+d\left(l_{1}\right)$, where $d(\cdot)$ is a weakly decreasing function. Set $\delta^{*}=\frac{1}{1+F\left(l_{2}(\theta)\right)} \geq 1 / 2$, and consider $\delta \leq \delta^{*}$. Using the definition of $l_{\sigma}$ and 
equation (8), we have that $b\left(l_{\sigma}\right)=\delta u_{2}(\theta)=\delta\left[b\left(l_{2}(\theta)\right)+\int_{0}^{l_{2}(\theta)} b(s) d F(s)\right] \leq \delta\left[b\left(l_{2}(\theta)\right)\left(1+F\left(l_{2}(\theta)\right)\right] \leq\right.$ $\delta^{*}\left[b\left(l_{2}(\theta)\right)\left(1+F\left(l_{2}(\theta)\right)\right]=b\left(l_{2}(\theta)\right)\right.$. Therefore, it must be that $l_{2}(\theta)>l_{\sigma}$. This fact together with the fact that $V_{1}\left(l_{1}\right)=V_{2}\left(l_{1}\right)+d\left(l_{1}\right)$ for $l_{1} \geq l_{\sigma}$ implies that $l_{1}(\theta) \leq l_{2}(\theta)$.

\section{References}

Aghion, P., Bolton, P., 1992. An incomplete contracts approach to financial contracting. Review of Economic Studies 59, 473-94.

Aghion, P., Dewatripont, M., Rey, P., 2004. Transferable control. Journal of the European Economic Association 2, 115-38.

Aghion, P., Tirole, J., 1997. Formal and real authority in organizations. Journal of Political Economy 105, $1-29$.

Alonso, R., Matouschek, N., 2008. Optimal delegation. The Review of Economic Studies 75, 259-93.

Boot, A., Greenbaum, S., Thakor, A., 1993. Reputation and discretion in financial contracting. American Economic Review 83, 1165-83.

Chevalier, J. Ellison, G., 1999. Career concerns and mutual fund managers. Quarterly Journal of Economics 114 , 389-432.

Crawford, V.P., Sobel, J., 1982. Strategic information transmission. Econometrica 50, 1431-51.

Dass, N., Massa, M., Patgiri, R., 2008. Mutual funds and bubbles: The surprising role of contractual incentives. Review of Financial Studies 21, 51-99.

Dessein, W., 2002. Authority and communication in organizations. The Review of Economic Studies 69, 811-38.

Ely, J. C., Välimäki, J., 2003. Bad reputation. Quarterly Journal of Economics 118, 785-814.

Englmaier, F., Filipi, A., Singh, R., 2010. Incentives, Reputation and the Allocation of Authority. CESifo Workingpaper No. 2979

Fama, E., 1980. Agency problems and the theory of the firm. Journal of Political Economy 88, 288-307.

Gibbons, R., Murphy, K., 1992. Optimal incentive contracts in the presence of career concerns: Theory and evidence. Journal of Political Economy 100, 468-505.

Grossman, S., Hart, O., 1986. The costs and benefits of ownership: A theory of vertical and lateral integration. Journal of Political Economy 94, 691-719.

Harris, M., Raviv, A., 1996. The capital budgeting process: Incentives and information. Journal of Finance 51, 1139-74.

Hart, O., Moore, J., 1990. Property rights and the nature of the firm. Journal of Political Economy 98, 1119-58.

Holmström, B., 1984. On the theory of delegation. In: Boyer, M., Kihlstrom, R. E. (Eds.). Bayesian Models in Economic Theory. Amsterdam: North-Holland, 115-41.

Holmström, B., 1999. Managerial incentive problems - a dynamic perspective. The Review of Economic Studies 66, 169-82.

Holmström, B., Milgrom, P., 1991. Multitask principal - agent analyses: Incentive contracts, asset ownership, and job design. Journal of Law, Economics and Organization 7, 24-52.

Holmström, B., Ricart i Costa, J., 1986. Managerial incentives and capital management. Quarterly Journal of Economics 101, 835-60. 
Ichino, A., Muehlheusser, G., 2008. How often should you open the door? Optimal monitoring to screen heterogeneous agents. Journal of Economic Behavior \& Organization 67, 820-31.

Jensen, M. C., Meckling, W. H., 1992. Specific and General Knowledge and Organizational Structure. In: Werin, L., Wijkander, H. (Eds.). Contract Economics. Oxford: Blackwell, 251-74.

Kaarbøe, O. M., Olsen, T. E., 2006. Career concerns, monetary incentives and job design. Scandinavian Journal of Economics 108, 299-316.

Kahn, L. M., Sherer, P. D., 1990. Contingent pay and managerial performance. Industrial and Labor Relations Review 43, 107S-120S.

Kaplan, S. N., Stromberg, P., 2003. Financial contracting theory meets the real world: An empirical analysis of venture capital contacts. The Review of Economic Studies 70, 281-315.

Kreps, D., Wilson, R., 1982. Sequential Equilibrium. Econometrica 50, 863-94.

Krishna, V., Morgan, J., 2008. Contracting for information under imperfect commitment. RAND Journal of Economics 39, 905-25.

La Porta, R., Lopez-de Silanes, F., Shleifer, A., Vishny, R., 1997. Legal determinants of external finance. Journal of Finance 52, 1131-50.

Magnan, M., St-Onge, S., 1997. Bank performance and executive compensation: A managerial discretion perspective. Strategic Management Journal 18, 573-81.

Nagar, V., 2002. Delegation and incentive compensation. The Accounting Review 77, 379-95.

Prendergast, C., 2002. The tenuous trade-off between risk and incentives. Journal of Political Economy 110, 1071-1102.

Scharfstein, D., Stein, J., 1990. Herd behavior and investment. American Economic Review 80, 465-79.

Shleifer, A., Vishny, R. W., 1997. A survey of corporate governance. Journal of Finance 52, 737-83.

Zwiebel, J., 1995. Corporate conservatism and relative compensation. Journal of Political Economy 103, 1-25. 